\title{
Power Quality and Performance Assessment of Grid- connected Photovoltaic Distributed Generation with Compliance to Stipulated Grid Integration Requirements
}

\author{
Fredrick Nkado and Franklin Nkado
}

\begin{abstract}
Recently, the demand for electrical energy has increased more than energy production due to the growing population and industrialization. Therefore, the distributed generators integration (DGs) into the distribution system has been widely adopted. This work examines the effect of photovoltaic-based distributed generator (PV-DG) integration on power quality effect of a radial distribution system. Firstly, the capacity and optimum placement of the PV-DG units in the distribution network are determined by employing the particle swarm optimization (PSO) algorithm. Then, the impact of PVDG integration on voltage harmonic distortion is analyzed by performing harmonic load flow analysis. Also, the P-V curve method is used to evaluate the effects of higher PV-DG penetration levels on loading margin and voltage magnitude. The simulation results show that as the PV-DG units' penetration level increases, a greater level of harmonic distortion is injected, implying that the PV-DG units should only be integrated up to the network's maximum capacity. Therefore, high harmonic distortion is produced when the PVDG units are penetrated beyond this maximum penetration level, which has a negative impact on the system's performance. The total voltage harmonic distortion is $4.17 \%$ and $4.24 \%$ at PCC1 and PCC2 at the highest penetration level, allowing the acceptable harmonic distortion limit. Also, grid-connected PVDG units improve loading margin and voltage magnitude, according to the P-V curve results. The standard IEEE-33 bus distribution system is modelled in ETAP software and is used as a test system for this study.
\end{abstract}

Key words - Distribution system, ETAP, PhotovoltaicDistribution Generation (PV-DG), P-V curve, Particle swarm optimization (PSO), Power quality.

\section{INTRODUCTION}

As loads become increasingly sensitive and nonlinear loads increase in the electrical distribution system, power quality becomes more important [1]. Compared with installing power plants to meet the new offsite load, Distributed Generators are seen as more cost-effective and environmentally friendly. The well-known and cost-effective sources of electric power generation include solar and wind energy. The DG can improve the power system by minimizing power losses, improving the voltage profile, increasing system efficiency, and avoiding system upgrades [2]. One of the advantages of DG units is that they can be installed close to load centres, unlike large central power

Submitted on October 14. 2021.

Published on November 04, 2021.

Fredrick Nkado, Xian Jiaotong University, China.

(e-mail: frednkado@stu.xjtu.edu.cn) generators. The power rating of PV-DG units ranges from $5.0 \mathrm{~kW}$ up to $100 \mathrm{MW}$.

PV systems, wind turbines, biomass, and small hydropower facilities can all be used as DGs. On the other side, an increased level of DG penetration could affect power system operation and control strategies. As a result, examining the DG system in conjunction with the loads is crucial to avoid voltage and frequency instability. Therefore, it is essential to consider voltage stability when planning for power system operation [3]. Harmonic distortion is also another undesired problem that must be considered while operating grid connected photovoltaic DGs. In a PV-DG system, an inverter converts direct current (DC) to alternating current (AC), injecting voltage and current harmonics into the system, resulting in poor power quality [4], [5]. Equipment overheating, which leads to increased power loss, equipment failure, operation failure, system malfunction, voltage fluctuation and equipment protection are some of the harmonics effects on power systems [6].

Multiple DG units can be integrated into the distribution power network to compensate for the reactive power reduction and improve voltage stability [7]. A photovoltaic system can be used in conjunction with one or more other generators. However, because the PV system's power generation is intermittent, adding more DG units can disrupt the voltage profile, especially on cloudy days, with a voltage collapse resulting in a complete power outage [8]. PV-DG units in power networks are divided into stand-alone and gridconnected based on their applications. Grid-connected applications can generate energy for local loads and exchange power with the utility grid, whilst stand-alone PV-DG units can only deliver electric power for remote loads without exchanging power with the utility grid [9], [10]. In gridconnected and stand-alone PV-DG systems, an inverter converts direct current from a PV module into alternating current. A PV-DG unit connected to the grid can inject excess energy back after meeting the load demand [11]. Fig. 1 illustrates the grid-connected PV-DG unit. In grid-connected PV-DG systems, the penetration level represents the overall PV-DG power injected into the grid. Therefore, PV-DG penetration level in percentage is defined as the ratio of PVDG power to the total system load demand, as stated in (1).

$$
\begin{aligned}
& P V-D G \text { penetration level }(\%)= \\
& \frac{\sum P V-D G \text { power }(M W)}{\sum \text { system load demand }} \times 100 \%
\end{aligned}
$$

Franklin Nkado, Auckland University of Technology, New Zealand (e-mail: nkadofranklin ${ }^{\circledR}$ gmail.com) 


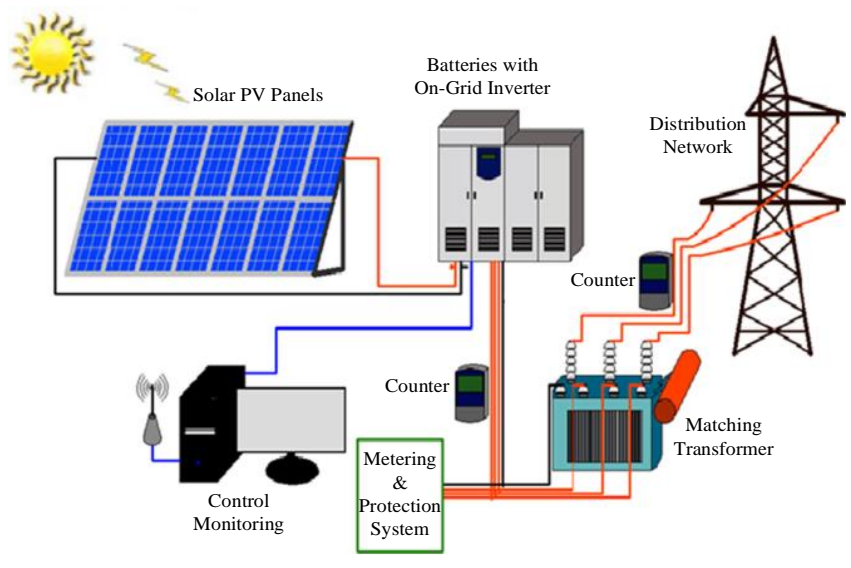

Fig. 1. Grid - connected PV system.

\section{LITERATURE REVIEW}

The effect of the high-penetration of PV-DG units on total harmonic distortion (THD) in a distribution network is presented and investigated in [11]. The result shows that high penetration levels of PV-DG units lead to increased harmonic distortion levels in distribution systems. To evaluate the power quality impact of grid-integrated PV-DG units in a distribution network, [10] proposed a 1.8 MW grid-connected PV-DG system for a 16-bus radial distribution network. The study shows that grid-connected PV-DG systems can lead to poor power quality of a distribution network. The total harmonic distortion (THD) is $14.27 \%$, which is above the IEEE-15 stipulated limit.

In [5], a power quality analysis of a grid-integrated solar PV system was carried out. This study focused on the effects on voltage and current quality in a PV integrated residential network. The analysis is carried out at different conditions without PV-DG penetration, maximum PV-DG penetration with average load, and minimum PVDG penetration with peak load. The results show that at feeders not close to transformers, voltage and current total harmonic distortion (THD) were more significant than feeders situated close to the transformers. However, the voltage and current THD values were high for the case of maximum PV power integration.

Study [12] has presented a harmonic analysis of large-scale renewable energy integration in a distribution network. This study considered $0 \%, 50 \%$, and $100 \%$ levels of gridconnected PV system penetration with $50 \%$ and $100 \%$ wind power penetration levels. As the level of RE penetration into the network increases, high harmonic distortion is observed to be produced. The current harmonic distortion level exceeded the permitted limits for $100 \%$ PV penetration and $50 \%$ and $100 \%$ wind penetration. At the same time, it was discovered that voltage harmonic distortion was within permissible limits. The impact of solar photovoltaic system integration in distribution networks has been conducted in [6]. The study analyzes the effects of different PV penetration levels in a distribution system on voltage harmonics. The simulation result shows that a higher PV system penetration level results in more voltage harmonic distortion. At the maximum PV system penetration level of $38.2 \%$, the voltage harmonic produced was $5 \%$ which is within an acceptable limit by IEEE-519.
According to the study [4], more PV penetration reduces voltage magnitude and increases loading margin, with $30 \%$ $\mathrm{PV}$ penetration resulting in the lowest grid loss. Few more parameters, such as solar temperature, solar irradiance, cloud shedding impact, and the unique design of the power system network, help support the effects on voltage stability at high PV penetration levels [13]. According to [14], voltage collapse can occur when a system is operated below permissible levels. Intermittent PV power output, on the other hand, creates voltage variations in the system.

This work focuses on the PV-DG units integration effects on distribution system voltage harmonics and voltage stability. A test system of the IEEE-33 radial distribution system is used while the P-V curve method is used for voltage stability analysis. All simulations and result analyses presented in this work are done in ETAP software.

\section{DESCRIPTION AND POTENTIALS OF SOLAR PHOTOVOLTAIC SYSTEM}

PV cell has low energy conversion efficiency, and their manufacturing process is costly [15]. The maximum power point tracking (MPPT) approach is used to determine the PV array's peak operating point. An MPPT regulates the solar PV interfaces and continuously extracts the maximum power from the PV array during changes in sunlight level, temperature, and PV module characteristics. Therefore, the purpose of an MPPT algorithm is to keep the solar operating voltage near its maximum operating point (MPP) during changes in atmospheric conditions [16]. As a result, PV power generation is reliable; also, it is easy to maintain because it has no moving parts. Therefore, their operating cost is very cheap.

Electrical energy is produced by cells in the PV module, and these cells depend on the solar energy photoelectric effects. Therefore, the PV cell is a significant building block of the PV system, and it is made of semiconductor materials that convert solar energy into direct current (DC). The PV cells make up the PV module which can be rated from 50 Watts to 450 Watts [17], [18]. The output voltage of a PV system is DC; therefore, a DC/AC power inverter is used to synchronize the PV system with the distribution system. Thus, an inverter unit is considered a significant part of the PV power generation, essential for stand-alone and gridconnected PV systems [19]. A Pulse Width Modulated Inverter (PWMI) Model is used to convert the PV output DC to 3-phase AC. Amongst multi-level inverters, the 12 pulses inverter and 6-pulses inverter have more practical uses. As illustrated in Fig. 2, the 12-pulse inverter has a smaller THD than other types of inverters (such as the 6-pulse inverter). The amount of waveform levels of the 12-pulse inverter contributes to this advantage. The waveform quality in a $12-$ pulses inverter is better than in a 6-pulses inverter, resulting in a nearly sinusoidal waveform. Adjusting the DC control voltages and the photovoltaic system output regulates the amplitude of the inverter output voltages [20]. 


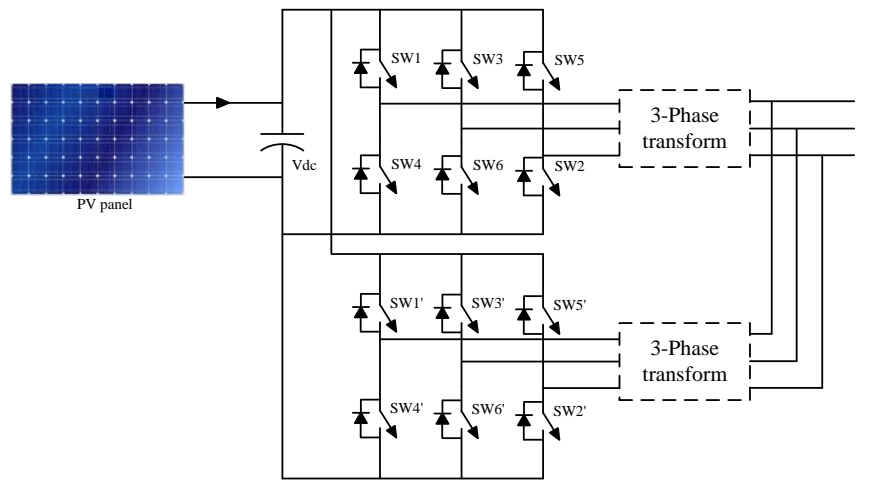

Fig. 2. DC-AC 12 pulses inverter.

\section{DG AlLOCATION SELECTION}

DG allocation is the major challenge in achieving the best system operation considering PV design environmental weather. As a result, choosing the best allocation is a significant optimization task for DGs design [21]. Once the allocation $\left(N_{D G s}\right)$ is made with the same DGs technology module and the number of feasible allocations is limited $\left(N_{B}\right)$. As a result, the number of DGs that can be combined is $\left(N_{C}\right)$ using (2). The number of possible DG unit combination $\left(N_{D}\right)$ can be evaluated using different DG technologies by applying (3). Therefore, it is essential to choose and find the ideal allocation and capacity of DG units in a power system network to achieve system stability at a minimal cost,

$N_{C}=\frac{N_{B} !}{N_{D G} ! *\left(N_{B}-N_{D G}\right) !}$

$N_{D}=\frac{N_{B} !}{\left(N_{B}-N_{D G}\right) !}$

The fundamental purpose of the optimization model is to minimize the divergence between terminal voltage and the specified voltage magnitude, which is called voltage Deviation (VD). Therefore, the terminal voltage amplitude is used to assess power quality and system security [22]. Furthermore, the reduction in voltage deviation can aid in maintaining the distribution system's optimal voltage level. Voltage deviation function can be determined using (4).

$\operatorname{Minf}_{3}(x)=\min \sum_{k=1}^{N_{h}}\left\{\sum_{k=0}^{N}\left(\frac{V_{i}^{k}-V_{i}^{k s p e c}}{V_{i}^{k m a x}-V_{i}^{k m i n}}\right)\right\}$

where, $V_{i}^{k}$ is the $i-t h$ busbar voltage amplitude of $k-t h$ period, $V_{i}^{k s p e c}$ is the specified voltage magnitude, and $V_{i}^{k \max }$ is the $i-t h$ busbar maximum voltage and $V_{i}^{k \min }$ is the $i-t h$ busbar minimum voltage.

\section{OPTIMUM PLACEMENT AND CAPACITY OF PV-DG UNITS IN A DISTRIBUTION SYSTEM}

The aim of optimising the size and placement of PV-DGs in a distribution program is to minimize penetration loss and improve the distribution system's voltage profile [23]. Particle swarm optimization (PSO) is a recently developed optimization technique with several features, including a minimum number of iterations with a short execution time to complete a process [24]. As a result, in this study, PSO is utilised to determine the best location and capacity for the required PV-DG units in the IEEE-33 bus radial distribution system. PSO is a reliable stochastic optimization algorithm that relies on swarm intelligence and movement. It's a population-based search technique that starts with a set of random solutions known as particles. Each member of a particle swarm optimization algorithm is referred to as a "particle". Each particle moves around in a large search space, with the particle's experience speed and that of its neighbor's, or the entire swarm [25]. PSO with a local neighborhood and PSO with a global neighborhood are two versions of the PSO algorithm created. As per the worldwide neighborhood, every particle advance towards its best former position and the best particle in the entire swarm known as the globally best model. On the other hand, the local variant reflects a ring social topology by causing each particle to return to its best former place.

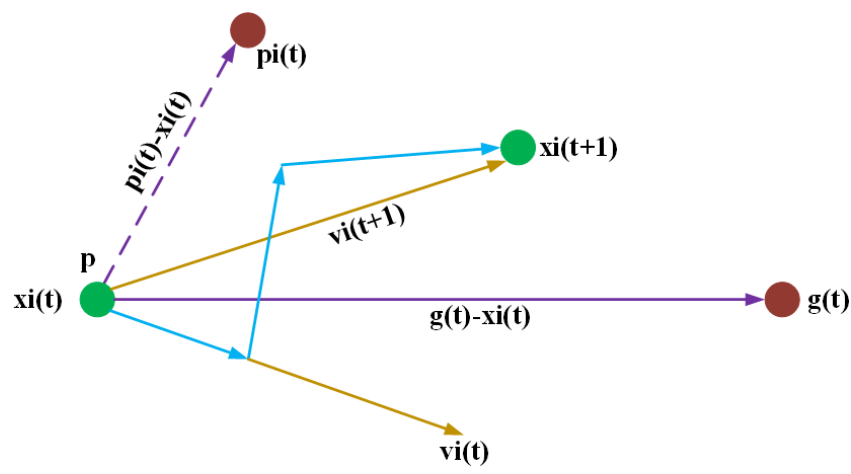

Fig. 3. Graphical illustration of PSO [26].

The genetic algorithm and the particle swarm optimization technique both start with a population of random solutions. Each potential solution in the PSO system, on the other hand, has a randomized velocity. Each particle begins with a random position and speed, then maintains a record of its coordinates in hyperspace to interact with other particles to obtain the optimum solution (fitness). Best is the name given to this value, which must be saved. There is another best value for the system called gbest, in addition to pbest. This is the global version of the particle swarm optimizer, which keeps track of all best values and their locations as achieved by any particle in the same population thus far [27]. Each particle attempts to update its location based on the following data: the current particle location $\left(X_{i}\right)$, current particle velocity $\left(V_{i}\right)$, distance between the current location $\&$ personal best $\left(P_{\text {pbest }}\right)$ and distance between the current location and global best $\left(P_{\text {gbest }}\right)$. Also, PSO is graphically depicted in Fig. 3 [28], [29].

$V_{i j}(t+1)=w \times v_{i j}(t)+r_{1} c_{1}\left(p_{i j}(t)-x_{i j}(t)\right)+$

$r_{c} c_{2}\left(g(t)-x_{i j}(t)\right)$

$x_{i j}(t+1)=v_{i j}(t+1)+x_{i j}(t)$

where $w$ is the inertia weight, and $r_{1}$ and $r_{c}$ are evenly distributed random values between 0 and 1 . Three significant elements make up the new velocity equation which are:

1) The inertia term element: $w * v_{i j}(t)$. 
2) The cognitive element: $r_{1} c_{1}\left(p_{i j}(t)-x_{i j}(t)\right)$.

3) The social element: $r_{c} c_{2}\left(g(t)-x_{i j}(t)\right)$.

Therefore, the prior location of the particles is transformed into a new place in the search space using this new velocity vector. This process is repeated until the total number of iterations is reached, as illustrated in Fig. 4.

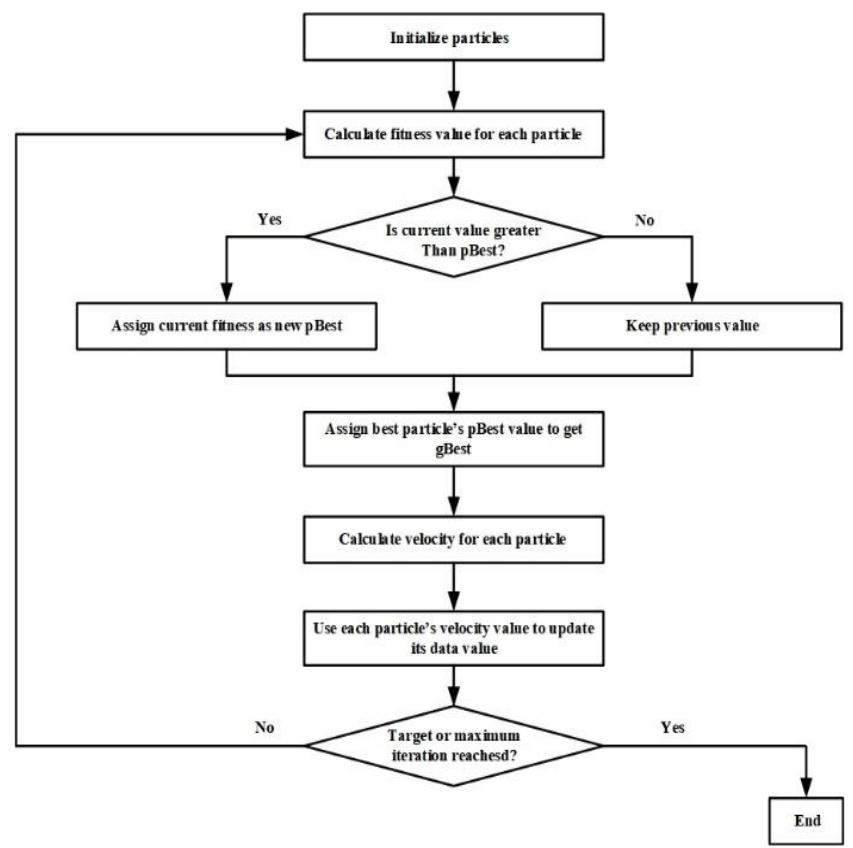

Fig. 4. PSO algorithm flowchart.

\section{MODELLING AND ANALYSIS OF A RADIAL DISTRIBUTION NETWORK}

For feeders with a radial network design, a backward/forward sweep-based power flow mechanism is used. The forward sweep is used to estimate node voltage from the sending end to the far end of the feeder and laterals, whereas the backwards sweep is used to estimate branch current and power summing from the far back to the sending end. Backward sweeps can be used to estimate node voltages in some techniques [25].

\section{A. Backward/Forward Sweep Load Flow Analysis Technique}

The backward/forward method relies on corresponding current injections and two derived matrices: the bus injection to the branch-current matrix and the branch-current to the bus-voltage matrix. The related current injection-based approach is more practicable for distribution systems. The complex load $S_{i}$ on the bus is given in (7).

$S_{L i}=P_{L i}+j Q_{L i}, i=1, \ldots, N$

The branch currents from loads to origin are summed for each iteration $k$. However, we must first estimate the current injected at each bus and the bus injection to branch-current (BIBC), connecting the bus-injected current to the branch current. The current injection at the $k^{\text {th }}$ iteration of the $i^{\text {th }}$ the bus is given in (8):

$I_{i}^{k}=I_{i}^{r}\left(V_{i}^{k}\right)+j I_{i}^{i}\left(V_{i}^{k}\right)=\left(\frac{s_{i}}{V_{i}^{k}}\right)^{*}=\left(\frac{P_{i}+j Q_{i}}{V_{i}^{k}}\right)^{*}$ where $V_{i}^{k}$ and $I_{i}^{k}$ represents the bus voltage and corresponding current injection of the $i^{\text {th }}$ bus at $k^{\text {th }}$ iteration. Also, $I_{i}^{r}$ and $I_{i}^{i}$ represents the real and imaginary parts of the corresponding current injection of bus $i$ at $k^{\text {th }}$ iteration.

\section{B. Problem Identification and Analysis}

Because of its simple structure and low running costs, the radial distribution system topology is commonly utilized to distribute electricity to end-users. However, because the end loads are so far from the substation, this type of distribution network results in significant power losses, particularly during peak load. As a result, the distribution line resistance corresponds with its length. Therefore, the optimum gridconnected PV-DG design aims to reduce active and reactive power losses by integrating solar energy near the far end buses. Distribution generators, which can improve power quality while meeting various constraints, are the best options for boosting distribution systems [30]. DG units are categorized into three modules based on their output characteristics: state variable reactive power, state variable active power and state reactive power and variable active power.

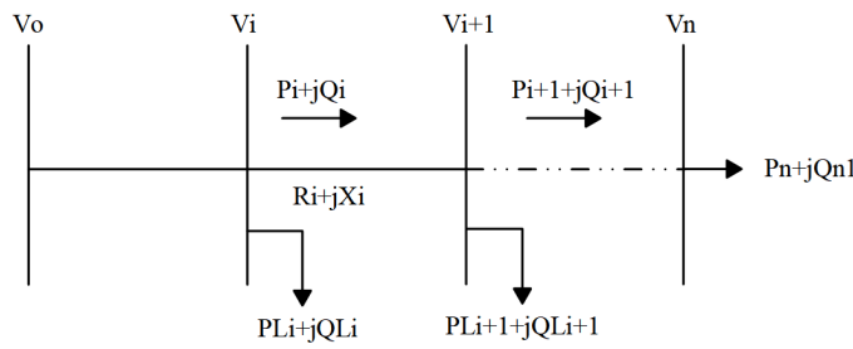

Fig. 5. Single line diagram of a distribution system

A more concise recursive equation connecting bus $i$ and $i+1$ is developed using the single line diagram of the radial distribution system presented in Fig. 5. First, the active and reactive powers between bus $i$ and $i+1$ before PV-DG units integration are given in (9) and (10). Then, the power loss in the line linking buses $i$ and $i+1$ is calculated in (11) and (12). Finally, the overall power losses of the system are calculated by summing the losses in different bus line sections understudy as given in (13) and (14).

$$
\begin{aligned}
& \mathrm{P}_{i+1}=\mathrm{P}_{i}-\mathrm{P}_{\text {Loss }, i}-\mathrm{P}_{l i+1}=\mathrm{P}_{i}-\frac{R_{i}}{V_{i}^{2}}\left(\mathrm{P}_{i}^{2}+\mathrm{Q}_{i}^{2}\right)-\mathrm{P}_{L i+1}(9) \\
& \mathrm{Q}_{i+1}=\mathrm{Q}_{i}-\mathrm{Q}_{\text {Loss }, i}-\mathrm{Q}_{L i+1}=\mathrm{Q}_{i}-\frac{X_{i}}{V_{i}^{2}}\left(\mathrm{P}_{i}^{2}+\mathrm{Q}_{i}^{2}\right)-\mathrm{Q}_{L i+1} \\
& \mathrm{P}_{\text {Loss }(i, i+1)}=\frac{R_{i}}{V_{i}^{2}}\left(\mathrm{P}_{i}^{2}+\mathrm{Q}_{i}^{2}\right) \\
& \mathrm{Q}_{\text {Loss }(i, i+1)}=\frac{X_{i}}{V_{i}^{2}}\left(\mathrm{P}_{i}^{2}+\mathrm{Q}_{i}^{2}\right) \\
& \mathrm{P}_{T, \text { Loss }}=\sum_{i=1}^{N} \frac{R_{i}}{V_{i}^{2}}\left(\mathrm{P}_{i}^{2}+\mathrm{Q}_{i}^{2}\right) \\
& \mathrm{Q}_{T, \text { Loss }}=\sum_{i=1}^{N} \frac{X_{i}}{V_{i}^{2}}\left(\mathrm{P}_{i}^{2}+\mathrm{Q}_{i}^{2}\right)
\end{aligned}
$$


The previous power loss reduction Equations can be modified for the PV-DG units integrated distribution system, as shown in Fig. 6. The modified Equations are given in (15) and (16).

$\mathrm{P}_{\mathrm{DG}, \text { Loss },(i, i+1)}=\frac{\left(P_{i-P_{\mathrm{DG}}}\right)^{2}+Q_{i}^{2}}{V_{i}^{2}} R_{i}$

$\mathrm{Q}_{\mathrm{DG}, L o s s,(i, i+1)}=\frac{\left(P_{i-P_{\mathrm{DG}}}\right)^{2}+Q_{i}^{2}}{V_{i}^{2}} X_{i}$

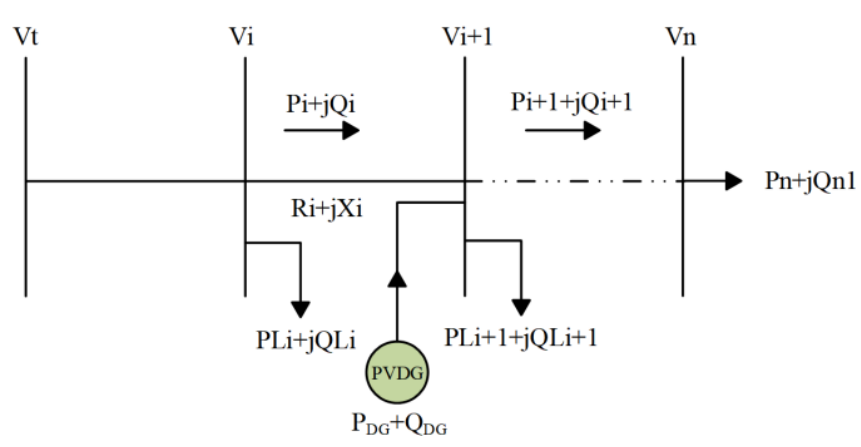

Fig. 6. Line diagram of a distribution system integrated with PV-DG.

\section{PV-DG Integration Operational Limits}

PV-DGs integration into the distribution system needs to meet specific stipulated standards by IEEE. For example, the voltage magnitudes threshold should be maintained between 0.95 p.u and 1.05 p.u. The maximum limit based on the IEEE standard limits the operational range of total and individual harmonic distortions. The objective function is expressed in (17) and (18).

$$
\begin{aligned}
& \text { Maximize: } F=W_{1} \times \Delta P_{\text {loss }}^{P V-D G}+W_{2} \times \Delta Q_{\text {loss }}^{P V-D G}+ \\
& W_{3} \times \sum_{i=1}^{n}\left(V_{i}-1\right)^{2}
\end{aligned}
$$

Subject to:

$$
\left\{\begin{array}{c}
0.95 \leq V_{i} \leq 1.05 \\
P_{V} \leq P_{V, \max } \\
Q_{V} \leq Q_{V, \max } \\
W_{1}+W_{2}+W_{3}=1
\end{array}\right.
$$

where $W_{1}+W_{2}+W_{3}$. The voltage deviation is included as a maximization problem in the above formulation, which means it approaches to zero when each bus voltage level is very close to unity. [23].

\section{Voltage Stability in a PV-DG Integrated Distribution Network}

The present power distribution networks continually face increased load demand which is prone to voltage collapse due to overloading conditions [31]. The distribution system must maintain appropriate voltages across all buses in both normal and abnormal situations for the distribution system to remain stable. The P-V curve is shown in Fig. 7, which describes the relationship between steady-state bus voltage and injected load power. A P-V curve assesses the PV-DG units' effect on power system voltage stability since PV-DG units actively support the system's power, increasing the active power margin. The curve also shows the maximum active power and minimum voltage magnitude a bus or system can maintain before collapsing due to a disturbance. As a result, the P-V curve assesses the PV-DG system's impact on network stability.

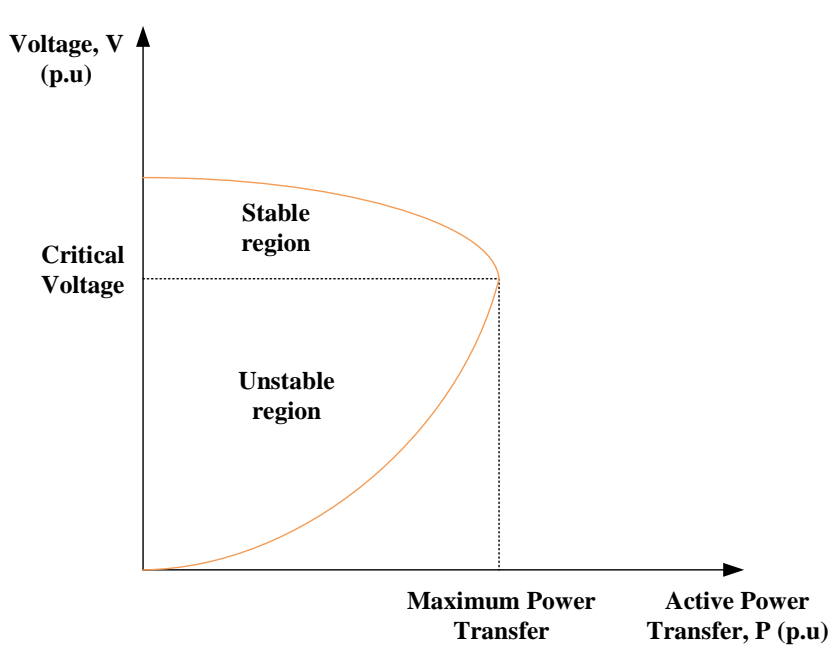

Fig. 7. P-V curve.

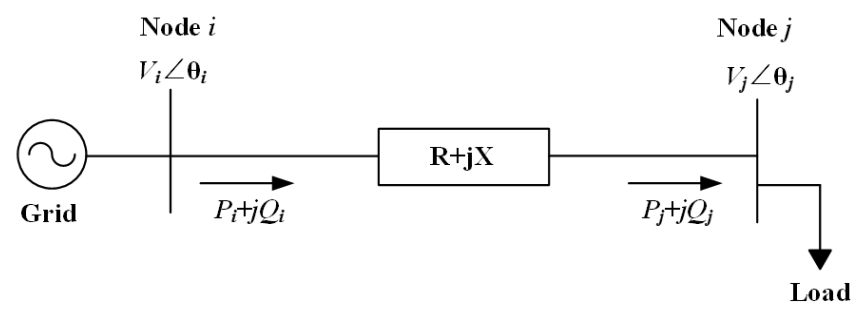

Fig. 8. Two-bus radial network.

Fig. 8 is an example of a lumped-parameter power line linking two buses in a distribution system. The receiving end voltage is represented by $V_{j}$, which is given in (19) [32] As can be seen in Fig. 7, solving $V_{i}^{2}$ in (19) provides two solutions of stable and an unstable quadratic equation. implementing the condition in (20) determines the stable solution of $V_{i}^{2} . V S I_{j}$ is estimated using (21). The critical $V S I$, i.e., $V S I_{c r}$ is zero as can determined by equations (20) and (21). Therefore, from (22), the minimum VSI of all buses is used to define the distribution system VSI.

$V_{j}^{2}+\left[2\left(P_{j} R+Q_{j} X\right)-V_{i}^{2}\right] V_{j}^{2}+$

$\left(P_{j}^{2}+Q_{j}^{2}\right)\left(R^{2}+X^{2}\right)=0$

$\left[2\left(P_{j} R+Q_{j} X\right)-V_{i}^{2}\right]^{2}-$

$4\left[\left(P_{j}^{2}+Q_{j}^{2}\right)\left(R^{2}+X^{2}\right)\right] \geq 0$

$V S I_{j}=\left[2\left(P_{j} R+Q_{j} X\right)-V_{i}^{2}\right]^{2}$

$-4\left[\left(P_{j}^{2}+Q_{j}^{2}\right)\left(R^{2}+X^{2}\right)\right]$

$V S I=\min \left[V S I_{1}, V S I_{2}, V S I_{3}, \ldots, V S I_{N}\right](22)$

The bus equivalence to the obtained VSI is the weakest bus, which means the bus voltage collapse can start. As a result, the voltage stability margin can be calculated based on the difference between $V S I$ and $V S I_{c r} . V S I_{j}$ can be computed by adding a PV-DG unit at bus $j$ using (23) as shown in Fig. 9. 


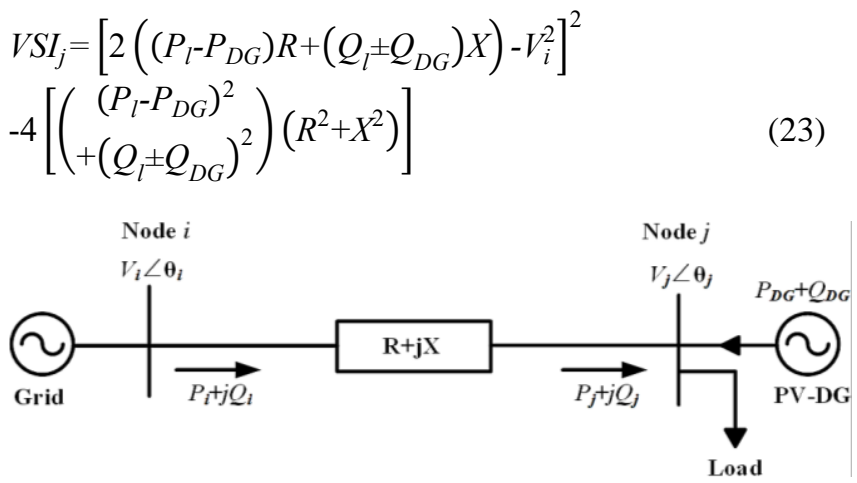

Fig. 9. PV-DG integration with existing radial network.

where $P_{l}$ and $Q_{l}$ represents the system load active and reactive powers; $P_{D G}$ and $Q_{D G}$ are the active and reactive powers of the PV-DG units. For the PV-DG units, the "+" and the "_." signs represent lagging and leading power factors. The $V S I_{j}$ in (19) can be expressed in a three-dimensional graph with adjustable PV-DG penetration levels and power factors when the upstream voltage, $V_{i}$, is considered to be $1.0 \mathrm{p}$.u, and the total load is assumed to be 1.0 p.u with a 0.8 power factor, as shown in Fig. 10.

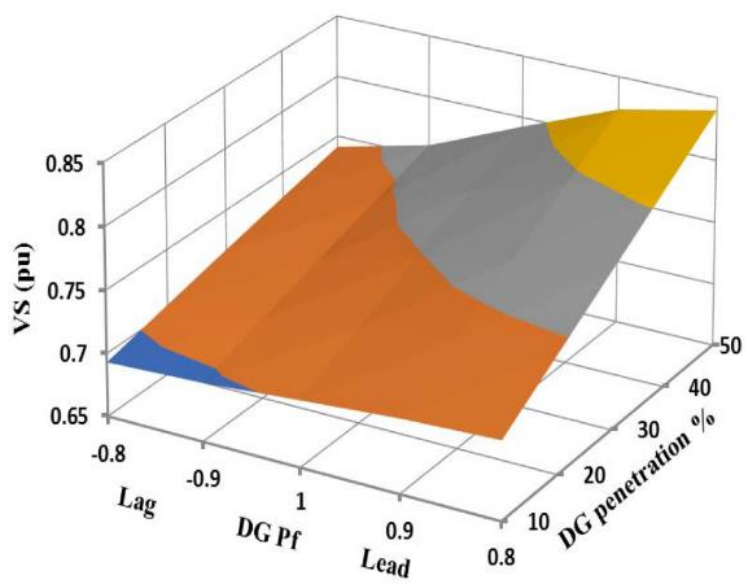

Fig. 10. VSI with DG at different power penetration and power factors [33].

Increasing DG penetration levels at leading power factors increases VSI and thus voltage stability, as shown in Fig. 10. However, the active power of the PV-DG units can be penetrated to a level that voltage stability is affected. Therefore, the system's power flow is affected by higher PVDG penetration levels, which could substantially impact the voltage stability of the power system.

\section{ANALYSIS OF HARMONIC DISTORTION IN A DISTRIBUTION SYSTEM}

When variable frequency devices, and other electronic equipment are connected to a distribution system, harmonics are produced. Electronic devices and nonlinear loads produce harmonics, which are integral multiples of the fundamental frequency. Electrical appliances such as transformers, capacitors, motor, generator heating, equipment functioning, and other issues that impair system performance can be severely harmed by high harmonic distortion in the network.
As a result, in order to have a secure and reliable system, the degree of harmonics in the system must be reduced [11].

The RMS value of the entire harmonic component of the output voltage divided by the RMS value of the fundamental component yields total harmonic distortion (THD). It's a measure indicating how close the output voltage waveform and its fundamental component are in terms of shape. An inverter is utilized to convert a DC input source to a required AC output. THD is a measure of the signal's output quality. THD is a method of comparing harmonics signals with the fundamental waveform. The generated harmonics can be even or odd. The number of pulses or conduction channels is likewise connected to even and odd harmonics. Odd harmonics are created in the signal when the negative half cycle is identical to the positive half cycle but in the opposite direction, and vice versa for even harmonics [34]. The harmonic order is given in (24).

$h=(n \times p) \pm 1$

where $h$ is the harmonic order, $n$ is an integer, and $p$ is the number of pulses in the circuit. Total harmonic distortion (THD) and Individual harmonic distortion (IHD) are widely used to assess a system's power quality [35]. The individual harmonic distortion is estimated with (25) for voltage signals, while the total harmonic distortion values for a voltage signal is calculated with (26). Table I present the voltage distortion limit at the point of common coupling (PCC) as recommended by IEEE-519 standard [36].

$$
\begin{aligned}
& \operatorname{IHD}_{v}(\%)=\frac{V_{h, r m s}}{V_{I, r m s}} \times 100 \\
& \operatorname{THD}_{v}(\%)=\frac{\sqrt{\sum_{n=2}^{\infty}\left(V_{n, r m s}\right)^{2}}}{\left(V_{1, r m s}\right)} \times 100
\end{aligned}
$$

TABLE I: VOLTAGE HARMONIC DisTORTION LIMITS [26]

\begin{tabular}{ccc}
\hline \hline $\begin{array}{c}\text { Bus voltage V at } \\
\text { PCC }\end{array}$ & $\begin{array}{c}\text { Individual harmonic } \\
\text { distortion }(\%)\end{array}$ & $\begin{array}{c}\text { Total harmonic } \\
\text { distortion THD (\%) }\end{array}$ \\
\hline $\mathrm{V} \leq 1.0 \mathrm{kV}$ & 5.0 & 8.0 \\
$1 \mathrm{kV}<\mathrm{V} \leq 69 \mathrm{kV}$ & 3.0 & 5.0 \\
$69 \mathrm{kV}<\mathrm{V} \leq 161 \mathrm{kV}$ & 1.5 & 2.5 \\
$161 \mathrm{kV}<\mathrm{V}$ & 1.0 & 1.5 \\
\hline \hline
\end{tabular}

\section{Simulation AND RESUlt Discussion}

All result presented in this paper is simulated in ETAP software. The IEEE-33 bus radial distribution network and PV-DG units are modelled in ETAP. The impact of integrating PV-DG units into the distribution system on harmonic distortion, power loss minimization, and loading margin is investigated at various PV-DG units penetration levels. Fig. 11 shows the ETAP model of the IEEE-33 radial distribution system integrated with PV-DG units. The distribution network complete data is listed in [29]. The system voltage level is $12.66 \mathrm{kV}$ while $\pm 5 \%$ is considered the upper and the lower voltage limit for all buses. The system's total demand is $3715 \mathrm{~kW}$ active power and $2300 \mathrm{kVar}$ reactive power, while the active and reactive power loss is $211 \mathrm{~kW}$ and $143 \mathrm{kVar}$. The PV-DG units are designed with a 0.95 power factor and with unlimited reactive power 
capabilities. Using the PSO technique, the optimum capacity of the PV-DG unit is determined as $1486 \mathrm{~kW}$, which corresponds to a $40 \%$ penetration level. Also, the PV-DG units' position in the distribution network is determined to be at buses 18 and 32 at $20 \%$ penetration level for each PV-DG unit. Therefore, buses 18 and 32 are taken as the points of common coupling, i.e., "PCC1" and "PCC2", respectively in the distribution network.

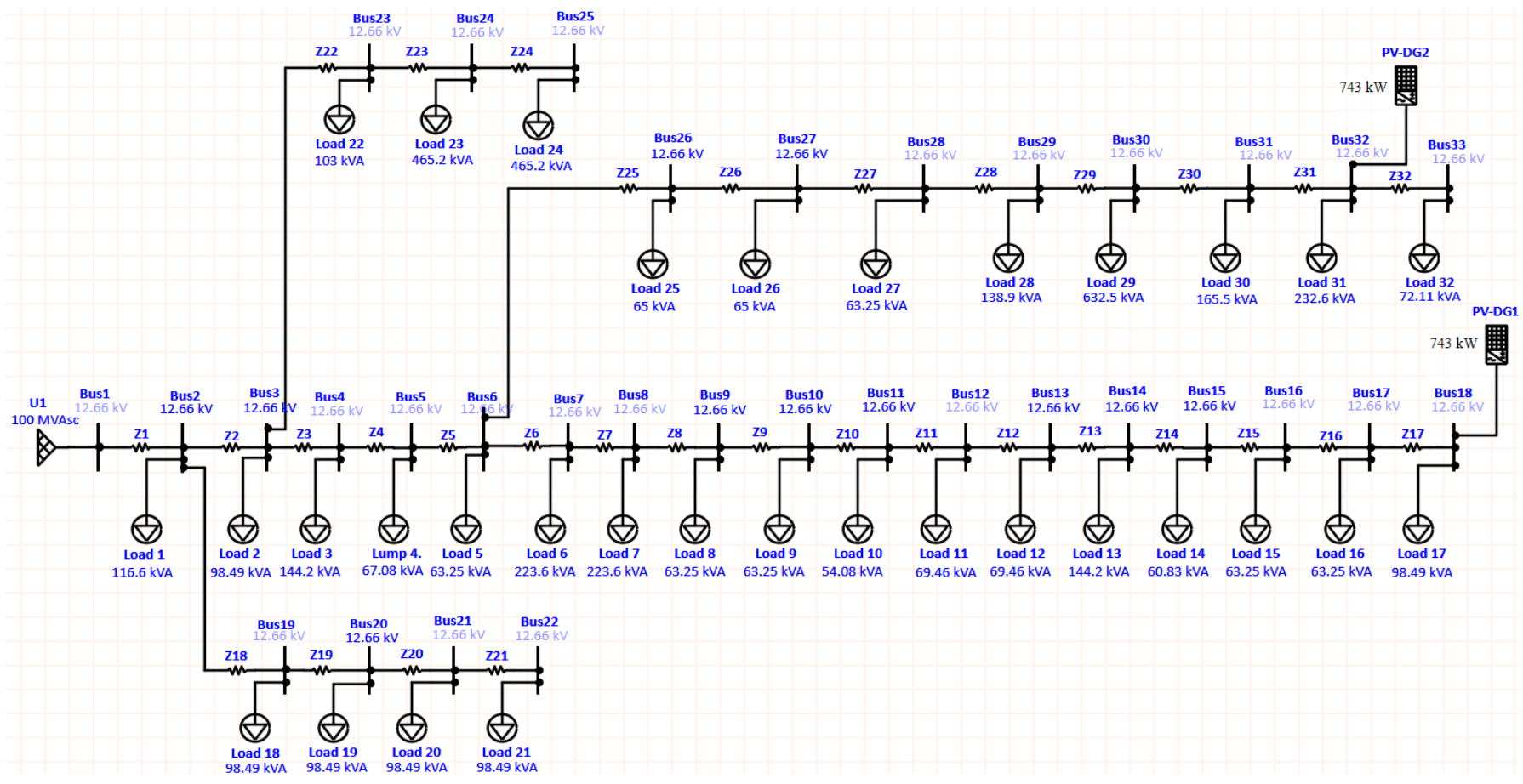

Fig. 11. IEEE-33 radial distribution system with PV-DG units.

\section{A. Effect of PV-DG Integration on Voltage Profile and Power Losses.}

Fig. 12 shows the voltage profiles of the distribution network before and after optimization. The voltage profiles of all the buses were improved to an acceptable limit after integrating two PV-DG units at buses 18 and 32, representing PCC1 and PCC2. In addition, Fig. 13 shows the total active and reactive power losses in the network before and after integrating two PV-DG units at PCC1 and PCC2 at 20\% penetration levels for each PV-DG system. Fig. 13 shows that the distribution network's active and reactive power losses were decreased by $76.3 \%$ and $72 \%$, respectively.

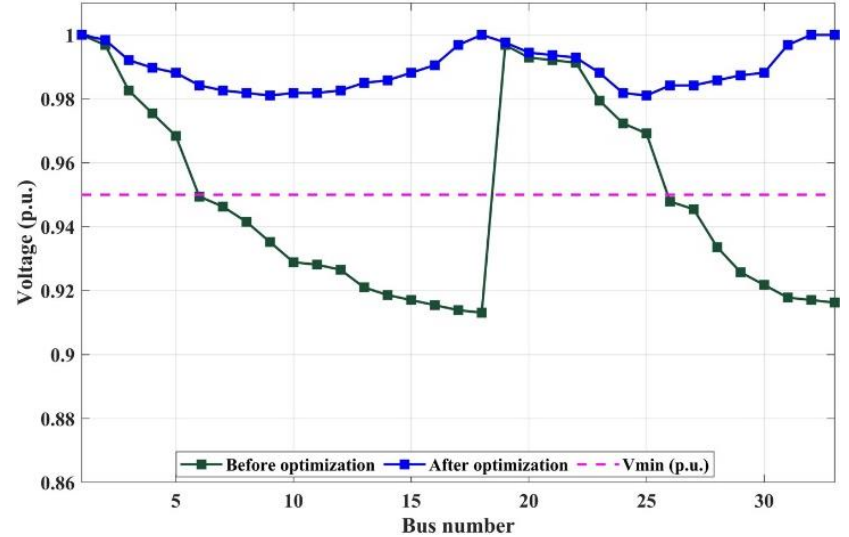

Fig. 12. Improved voltage profile after PV-DGs integration.

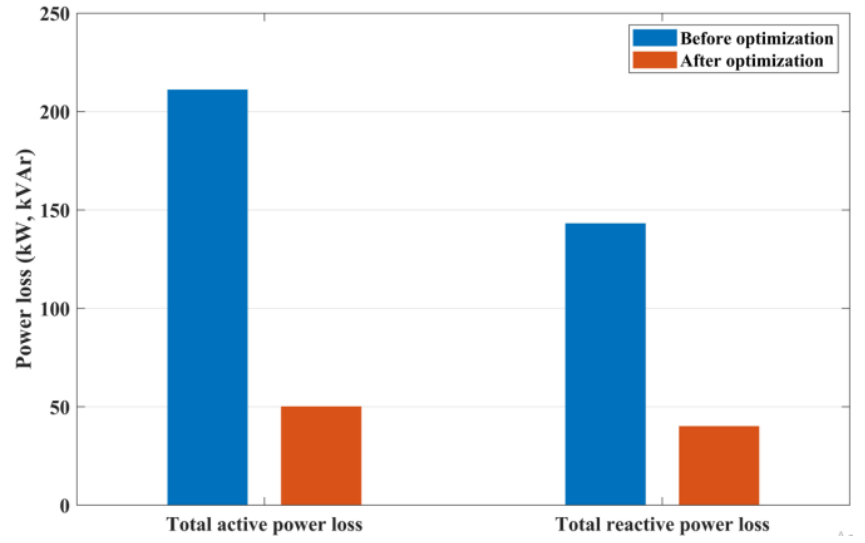

Fig. 13. Power loss reduction after PV-DGs integration.

\section{B. Effect of PV-DG Integration on Voltage Stability}

$\mathrm{P}-\mathrm{V}$ curve is performed to evaluate the effect of PV-DG integration on bus voltage magnitude and loading margin. The P-V curves of four selected buses without PV-DG integration is shown in Fig. 14. Three of the four buses considered are at the ends of each branch, with one bus located in the center of the network. Bus 18 is identified as the weakest bus. Load increments are unpredictable in an actual operating situation because they may increase in some buses while remaining constant in others. Evaluating such a complicated loading pattern, however, is difficult. As a result, for P-V curve analysis, all loads are increased simultaneously with a fixed loading factor until power flow ceases converging. 


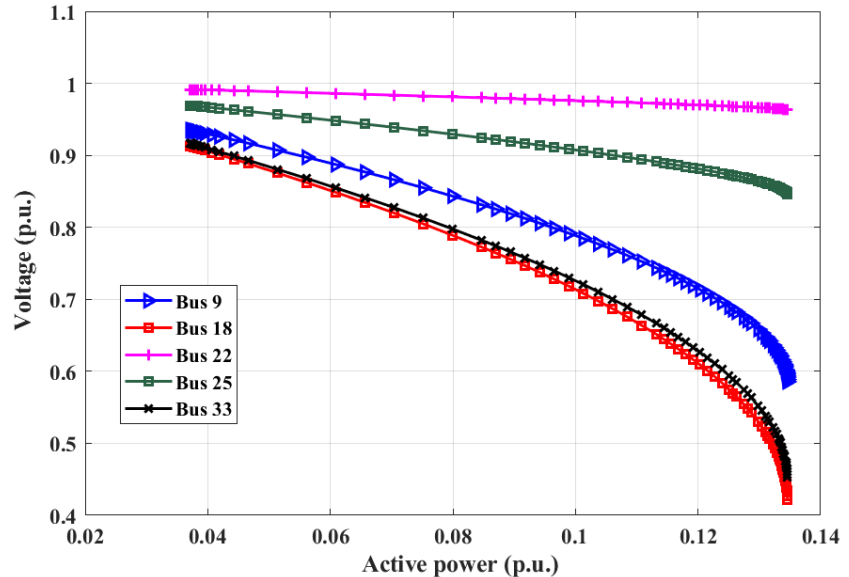

Fig. 14. P-V curves without PV-DGs integration.

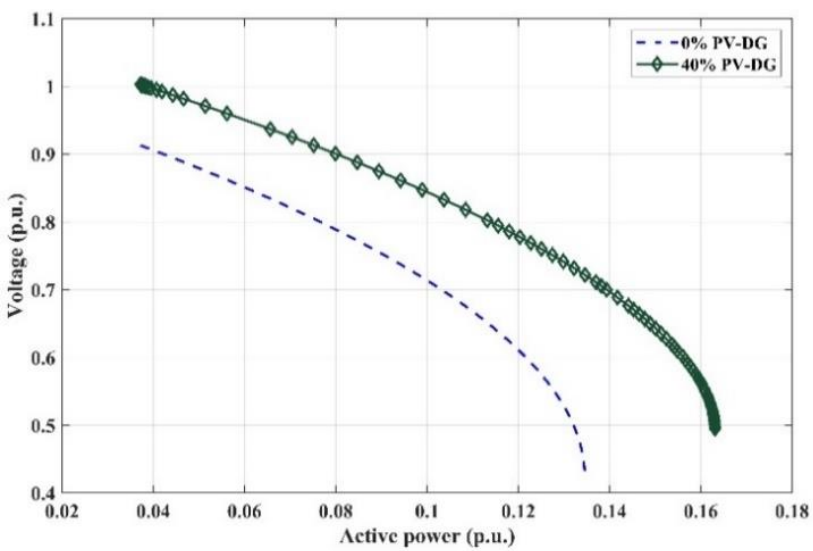

Fig. 15. P-V curve of Bus 18 with integrated PV-DG.

The P-V curve of only bus 18 is shown when PV-DG units were connected to the network to avoid repetition. The comparison of active power margin in Bus 18 between $0 \%$ PV-DG penetration and 40\% PV-DG penetration is shown in Fig. 15. In the first case, the maximum loading margin is 0.13 p.u with a voltage magnitude of 0.42 p.u. At $40 \%$ PV-DG integration, the loading margin increases by $21.2 \%$, while the voltage magnitude increases by $17.4 \%$. Also, the effect of increased penetration level of PV-DG units is analyzed on Bus 18 using the P-V curve. Various PV-DG capacity for different penetration levels is calculated using (1) as shown in Table II. Fig. 16 shows that at $80 \%$ PV-DG penetration level, the power margin is $0.19 \mathrm{p} . \mathrm{u}$, which is a $40 \%$ increment. Also, the voltage magnitude improves to $0.56 \mathrm{p} . \mathrm{u}$ from the base case value of 0.42 p.u. This demonstrates that a higher PV-DG penetration level provides a system with a reasonable load margin and voltage magnitude.

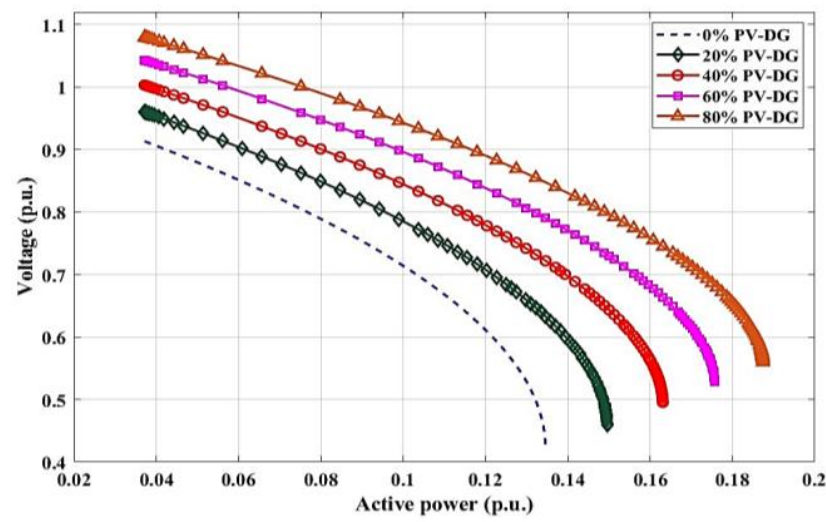

Fig. 16. P-V curve of Bus 18 at a varying PV-DG penetration level.

\begin{tabular}{cc}
\hline $\begin{array}{c}\text { TABLE II: VARIOUS PV-DG PENETRATION LEVEL } \\
\text { PV-DG penetration } \\
\text { level }(\%)\end{array}$ & $\begin{array}{c}\text { PV-DG generation } \\
(\mathrm{kW})\end{array}$ \\
\hline 20 & 743 \\
40 & 1,486 \\
60 & 2,229 \\
80 & 2,972 \\
\hline \hline
\end{tabular}

\section{Effect of PV-DG Integration on System Harmonic Distortion}

Different penetration levels of PV-DG units are performed to analyze their effect on system harmonic distortion. Largescale integration of PV-DG units into distribution systems can increase harmonic levels, destabilizing system operation. The total frequency spectrum and the waveform of maximum harmonic current generated by the PV-DG inverter are shown in Figs. 17, and 18. It extends up to 2500 kilohertz and has high harmonic distortion at $3^{\text {rd }}, 5^{\text {th }}, 7^{\text {th }}, 11^{\text {th }}$ and $13^{\text {th }}$. The capacity of PV-DG units connected to the distribution system must be adjusted until harmonic production does not exceed the acceptable operating limit. For harmonic analysis, the PVDG units are modelled as current sources.

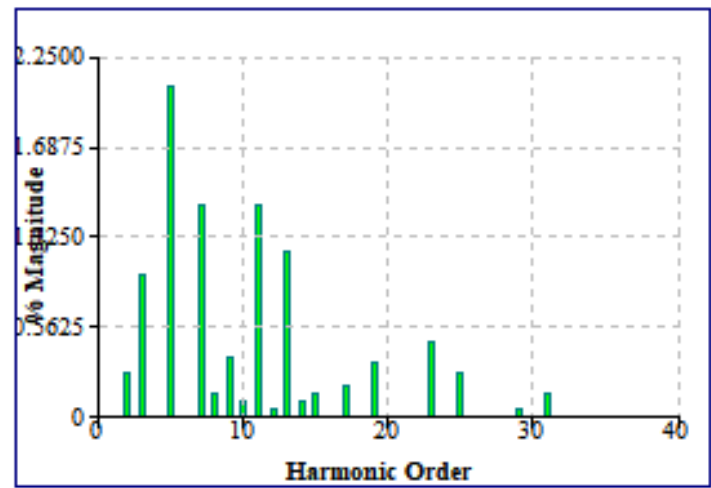

Fig. 17. The maximum harmonic current generated by PV-DG units.

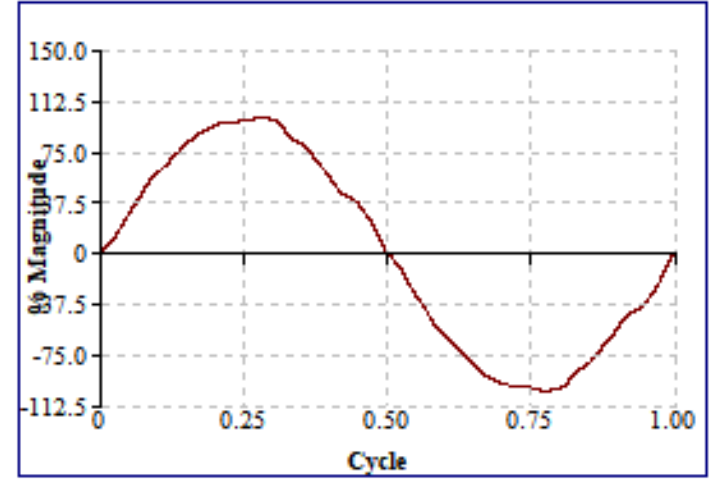

Fig. 18. The harmonic waveform of PV-DG units.

Fig. 19 shows the voltage total harmonic distortion $\operatorname{THD}_{v}(\%)$ at the two points of common coupling in the distribution network at different PV-DG penetration levels. Table I shows the acceptable total voltage distortion limit at the point of common coupling for different bus voltage levels. For this case analysis, the bus voltage is $12.66 \mathrm{kV}$. As a result, the maximum total bus voltage harmonic distortion allowed at PCC is $5 \%$. The test distribution network has a total voltage harmonic distortion of $0.42 \%$ at PCC1 and PCC2, respectively, for the base case. As shown in Fig. 19, the $0 \%$ to $40 \%$ penetration level of PV-DG units is within the IEEE 
standard's limits, while the $50 \%$ penetration level upwards surpassed the standard limit. It is noticed that total voltage harmonic distortion increased with higher PV-DG penetration levels. For minimum voltage distortion, the maximum penetration level of PV-DG power into the distribution network is predicted to be $45 \%$. The voltage distortions at this point are $4.17 \%$ and $4.24 \%$ at PCC1 and $\mathrm{PCC} 2$, which are within the acceptable stipulated limit. Figs. 20 and 21 show the harmonic spectrum and voltage waveform of buses 18 and 32 at maximum PV-DG penetration level.

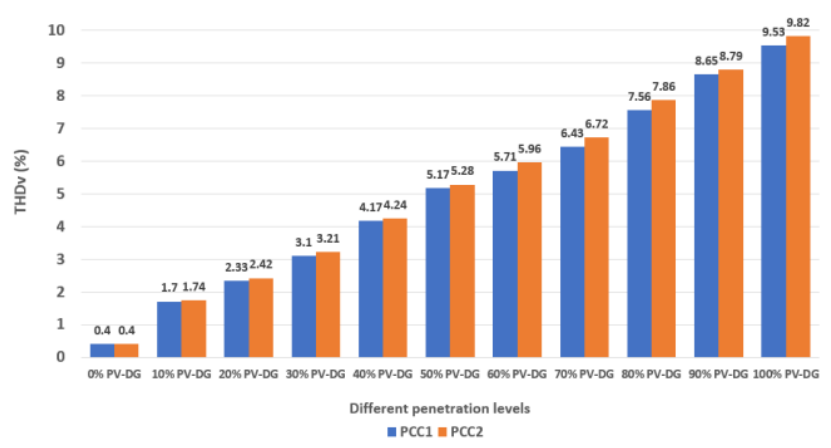

Fig. 19. $\mathrm{THD}_{v}$ under different penetration levels at $\mathrm{PCC} 1$ and $\mathrm{PCC} 2$.

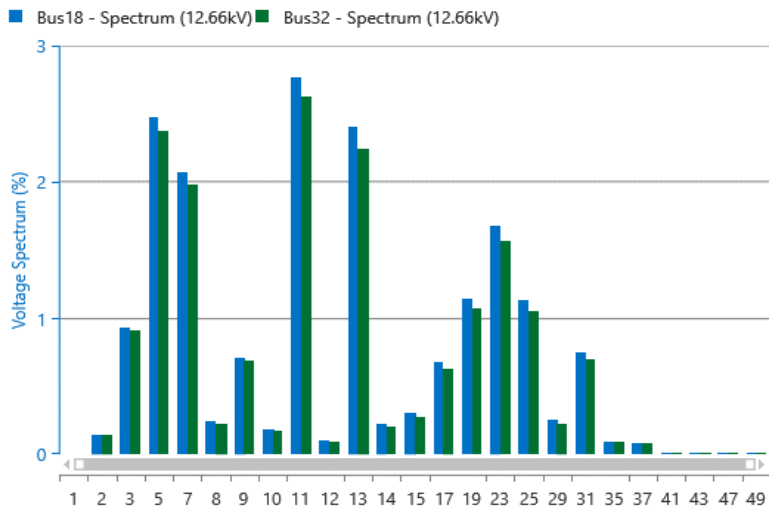
Harmonic Order

Fig. 20. Harmonic spectrum of Buses 18 and 32 at a maximum penetration level.

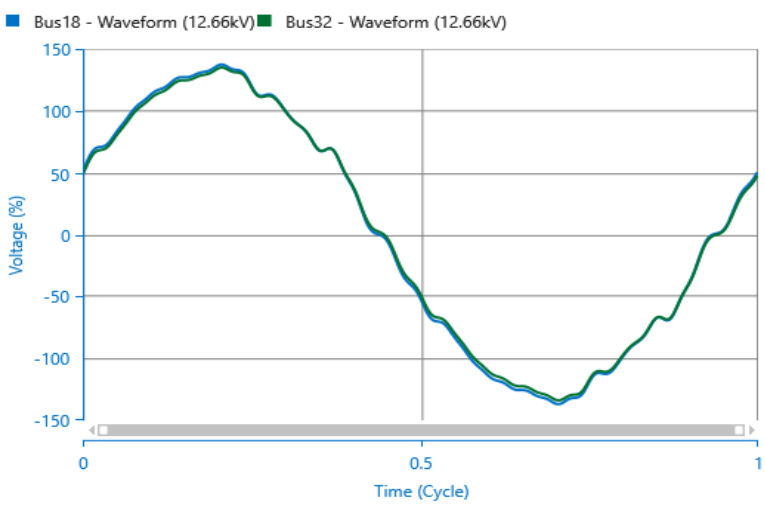

Fig. 21. The voltage waveform of Buses 18 and 32 at max penetration level.

\section{CONCLUSION}

The effect of PV-DG on the power quality of a radial distribution network is discussed in this paper. ETAP software is used to simulate the system on the IEEE-33 bus radial test distribution network. Particle Swarm Optimization (PSO) algorithm is used to select the optimum bus to connect the PV-DG units to the distribution network. Load flow analysis is performed to assess the network voltage profile improvement and power loss minimization percentage after PV-DG integration. The level of harmonic distortion is determined by varying the level of PV-DG power penetration into the feeder. Also, the P-V curve technique is used to analyze the system voltage stability at different PV-DG power penetration levels. The PV-DG power should be penetrated to the extent that the network's capacity allows. In this case, the total voltage harmonic distortion is used to determine the maximum penetration level of the PV-DG units, which is $40 \%$. At the maximum penetration level of PV-DG power, the total harmonic distortion level is $4.17 \%$ and $4.24 \%$ at PCC1 and PCC2, respectively. Finally, results show that connecting PV-DG unit into distribution network improves the loading margin and voltage magnitude.

\section{REFERENCES}

[1] A. Eltamaly, Y. Sayed, A. El-Sayed, and A. Elghaffar, "Adaptive static synchronous compensation techniques with the transmission system for optimum voltage control, " Ain Shams Eng J, ed, 2020.

[2] A. M. Eltamaly, M. A. Mohamed, and A. I. J. S. E. Alolah, "A novel smart grid theory for optimal sizing of hybrid renewable energy systems," Solar Energy, vol. 124, pp. 26-38, 2016.

[3] A. M. Eltamaly, M. A. Mohamed, M. Al-Saud, and A. I. J. E. O. Alolah, "Load management as a smart grid concept for sizing and designing of hybrid renewable energy systems," Engineering Optimization, vol. 49, no. 10, pp. 1813-1828, 2017.

[4] S. Eftekharnejad, V. Vittal, G. T. Heydt, B. Keel, and J. J. I. t. o. p. s. Loehr, "Impact of increased penetration of photovoltaic generation on power systems," Power Systems, IEEE Transactions, vol. 28, no. 2, pp. 893-901, 2012

[5] S. S. Kumary, V. A. A. M. T. Oo, G. Shafiullah, and A. Stojcevski, "Modelling and power quality analysis of a grid-connected solar PV system," in 2014 Australasian Universities Power Engineering Conference (AUPEC), 2014, pp. 1-6: IEEE

[6] R. Sahoo and S. J. I. J. o. A. E. R. Kulkarni, "Impact of Photovoltaic Penetration on Distribution Systems," IEEE, vol. 14, no. 11, pp. 2596 2601, 2019.

[7] A. Eltamaly, Y. Sayed, A.-H. El-Sayed, and A. N. A. J. A. o. F. E. J. I Elghaffar, "Multi-control module static VAR compensation techniques for enhancement of power system quality," ANNALS of Faculty Engineering Hunedoara - International Journal of Engineering, tom XVI, pp. 47-51, 2018.

[8] M. A. Hossain, H. R. Pota, M. J. Hossain, F. J. I. J. o. E. P. Blaabjerg, and E. Systems, "Evolution of microgrids with converter-interfaced generations: Challenges and opportunities," International Journal of Electrical Power \& Energy Systems , vol. 109, pp. 160-186, 2019.

[9] L. Xiong, M. Nour, E. J. I. J. o. C. Radwan, and D. Systems, "Harmonic Analysis of Photovoltaic Generation in Distribution Network and Design of Adaptive Filter," IJCDS Journal, vol. 9, no. 1, 2020.

[10] M. Farhoodnea, A. Mohamed, H. Shareef, and H. Zayandehroodi, "Power quality impact of grid-connected photovoltaic generation system in distribution networks," in 2012 IEEE Student Conference on Research and Development (SCOReD), 2012, pp. 1-6: IEEE.

[11] S. Pawar, "Harmonic analysis of high penetration pv system on grid," 2019.

[12] G. Shafiullah and A. M. Oo, "Analysis of harmonics with renewable energy integration into the distribution network," in 2015 IEEE Innovative Smart Grid Technologies-Asia (ISGT ASIA), 2015, pp. 1-6: IEEE.

[13] R. Yan and T. K. J. I. t. o. p. s. Saha, "Investigation of voltage stability for residential customers due to high photovoltaic penetrations," IEEE vol. 27, no. 2, pp. 651-662, 2012 .

[14] Y. Xue, M. Manjrekar, C. Lin, M. Tamayo, and J. N. Jiang, "Voltage stability and sensitivity analysis of grid-connected photovoltaic systems," in 2011 IEEE Power and Energy Society General Meeting, 2011, pp. 1-7: IEEE.

[15] K.-H. Kim, Y.-J. Lee, S.-B. Rhee, S.-K. Lee, and S.-K. You, "Dispersed generator placement using fuzzy-GA in distribution systems," in IEEE Power Engineering Society Summer Meeting, 2002, vol. 3, pp. 11481153: IEEE. 
[16] G. Carpinelli, G. Celli, F. Pilo, and A. Russo, "Distributed generation siting and sizing under uncertainty," in 2001 IEEE Porto Power Tech Proceedings (Cat. No. 01EX502), 2001, vol. 4, p. 7 pp. vol. 4: IEEE.

[17] C. Wang and M. H. J. I. T. o. P. s. Nehrir, "Analytical approaches for optimal placement of distributed generation sources in power systems," IEEE, vol. 19, no. 4, pp. 2068-2076, 2004.

[18] T. Ackermann, G. Andersson, and L. J. E. p. s. r. Söder, "Distributed generation: a definition," Electric Power Systems Research, vol. 57, no. 3, pp. 195-204, 2001.

[19] C. Mehdipour and F. J. J. o. S. E. R. Mohammadi, "Design and analysis of a stand-alone photovoltaic system for footbridge lighting," Journal of Solar Energy Engineering, vol. 4, no. 2, pp. 85-91, 2019.

[20] H. Hosseini, M. Farsadi, A. Lak, H. Ghahramani, N. J. I. J. o. T. Razmjooy, and P. P. o. Engineering, "A novel method using imperialist competitive algorithm (ICA) for controlling pitch angle in hybrid wind and PV array energy production system," International Journal on "Technical and Physical Problems of Engineering"(IJTPE), vol. 11, pp. 145-152, 2012.

[21] M. A. Mohamed and A. M. Eltamaly, "A novel smart grid application for optimal sizing of hybrid renewable energy systems," in Modeling and Simulation of Smart Grid Integrated with Hybrid Renewable Energy Systems: Springer, 2018, pp. 39-51.

[22] K.-y. Liu, W. Sheng, Y. Liu, X. Meng, Y. J. I. J. o. E. P. Liu, and E. Systems, "Optimal sitting and sizing of DGs in distribution system considering time sequence characteristics of loads and DGs," International Journal of Electrical Power \& Energy Systems, vol. 69, pp. 430-440, 2015.

[23] N. S. Rau and Y.-h. J. I. T. o. P. s. Wan, "Optimum location of resources in distributed planning," IEEE, vol. 9, no. 4, pp. 2014-2020, 1994.

[24] M. AlRashidi, M. AlHajri, A. Al-Othman, and K. El-Naggar, "Particle swarm optimization and its applications in power systems," in Computational intelligence in power engineering: Springer, 2010, pp. 295-324.

[25] S. Devi, M. J. I. J. o. E. P. Geethanjali, and E. Systems, "Optimal location and sizing determination of Distributed Generation and DSTATCOM using Particle Swarm Optimization algorithm," International Journal of Electrical Power \& Energy Systems, vol. 62 , pp. 562-570, 2014

[26] E. A. Sharew, H. A. Kefale, and Y. G. J. I. J. o. P. Werkie, "Power Quality and Performance Analysis of Grid-Connected Solar PV System Based on Recent Grid Integration Requirements," International Journal of Photoenergy, vol. 2021, 2021.

[27] M. Abdel-Salam, M. T. El-Mohandes, and E. Shaker, "PSO-based performance improvement of distribution systems using DG sources," in 2016 Eighteenth International Middle East Power Systems Conference (MEPCON), 2016, pp. 866-870: IEEE.

[28] H. A. Kefale, E. M. Getie, and K. G. J. I. J. o. P. Eshetie, "Optimal design of grid-connected solar photovoltaic system using selective particle swarm optimization," International Journal of Photoenergy, vol. 2021, 2021.

[29] M. J. Tahir, I. A. Latiff, M. Alam, and M. Mazliham, "Network reconfiguration using modified particle swarm algorithm," in 2018 2nd International Conference on Smart Sensors and Application (ICSSA), 2018, pp. 1-5: IEEE.

[30] K. V. Bhadane, M. Ballal, R. Moharil, and H. J. J. E. S. T. Suryawanshi, "Enhancement of distributed generation by using custom power device," Journal of Electronic Science and Technology, vol. 13, no. 3 , pp. 246-254, 2015.

[31] H. Hedayati, S. Nabaviniaki, Akbarimajd, and A. J. I. t. o. p. d. Akbarimajd, "A method for placement of DG units in distribution networks,"IEEE, vol. 23, no. 3, pp. 1620-1628, 2008.

[32] M. M. Aly and M. J. E. E. Abdel-Akher, "A robust quasi-direct continuous power-flow analysis using two-bus equivalents for voltage stability analysis of radial distribution systems," Electrical Engineering, vol. 100, no. 1, pp. 47-57, 2018.

[33] S. M. Said, B. Hartmann, M. M. Aly, M. Mosa, and R. S. Balog, "Comparison between operating modes of distributed generation on voltage profile and stability of distribution systems," in 2018 IEEE Texas Power and Energy Conference (TPEC), 2018, pp. 1-6: IEEE.

[34] E. Ciprés Lechuga, "Analysis of the implementation of a photovoltaic plant in Catalonia," 2010.

[35] A. A. Kadir, A. Mohamed, and H. Shareef, "Harmonic impact of grid connected photovoltaic inverters on $13.8 \mathrm{kv}$ distribution system," in Regional Engineering Postgraduate Conference EPC, 2010, pp. $367-$ 373.

[36] I. Std, "Recommended Practices and Requirements for Harmonic Control in Electrical Power Systems," IEEE Industry Applications Society. 